\title{
Assessment of Pyrethroid Pesticides in Topsoils in Northern Portugal
}

\author{
Idalina Bragança • Paulo C. Lemos • \\ Cristina Delerue-Matos • Valentina F. Domingues
}

\begin{abstract}
Pyrethroid insecticides are emerging contaminants broadly used for insect pest control in agriculture, veterinary, and domestic applications. Limited information can be found in literature regarding pyrethroid pesticide soil contamination in playgrounds and agricultural areas. The focus of this study was on new findings related to the spatial and seasonal occurrence of pyrethroid pesticide contamination in soils of northern Portugal. The soils were tested during summer and winter seasons. Pyrethroid pesticides were not found in the ten playgrounds sampled during both seasons. For the 18 agricultural soil samples tested, deltamethrin was the only pyrethroid detected, just during the summer season. For those, three of the samples taken were found to be positive with concentrations between 15.7 and $101.7 \mathrm{ng} \mathrm{g}^{-1}$. The results denote the need for monitoring and assessment of pyrethroid pesticide contamination in Portuguese soil. Further research is needed to access the ecological potential impact of pyrethroid pesticides on soil.
\end{abstract}

Electronic supplementary material The online version of this article (https://doi.org/10.1007/s11270-019-4209-7) contains supplementary material, which is available to authorized users.

I. Bragança · C. Delerue-Matos · V. F. Domingues $(\bowtie)$ REQUIMTE/LAQV-GRAQ, Instituto Superior de Engenharia do Porto, Instituto Politécnico do Porto, Rua Dr. António Bernardino de Almeida, 431, 4200-072 Porto, Portugal e-mail: vfd@isep.ipp.pt

P. C. Lemos

REQUIMTE/LAQV, Chemistry Dept., FCT/Universidade NOVA de Lisboa, Campus de Caparica, 2829-516 Caparica, Portugal
Keywords Soils $\cdot$ Pyrethroids · Deltamethrin . Agriculture · Playground

\section{Introduction}

Synthetic pyrethroids (SPs) show enhanced persistence and toxicity. They are chemical pesticides modified from pyrethrins, compounds naturally present in chrysanthemum flowers (Palmquist et al. 2012). SPs can be classified into two different types: type I if they are non-cyano pyrethroids or type II if they have the presence of the cyano group. SPs can also be classified as insecticides according to the type of organisms they act against, as they are used for insect pest control in agriculture, public, and animal health (Pfeil 2014; Albaseer et al. 2011). Their wide use is due to being considered one of the safest insecticides presently accessible for agricultural and public health purposes (Nicolopoulou-Stamati et al. 2016). The mechanism of action of SPs is based on altering the normal nervous system function of insects and other invertebrates and modifying the kinetics of voltage-sensitive sodium channels, leading to the knockdown of their normal functioning and eventually causing death (Soderlund 2010).

Abundant evidence of pyrethroid effects studied in animal models shows plausible outcomes that can be 
transposed to humans (Burns and Pastoor 2018). Studies using rats as model organisms suggested that pyrethroids can contribute to the etiology of Parkinson's disease, due to their environmental inductive component (Nasuti et al. 2007), by stimulating cognitive deficits (Nasuti et al. 2013). Children are particularly sensitive to environmental contamination with pesticides. They are susceptible to the uptake and to the adverse effects of such compounds because of developmental, dietary, and physiological factors. Studies suggest that exposure to pyrethroid pesticides might be associated with the increased risk of brain tumors in childhood (Chen et al. 2016) and also the correlation of pyrethroid metabolites with autism spectrum disorder (Domingues et al. 2016).

More than a dozen registered pyrethroid molecules are used in innumerable products (Burns and Pastoor 2018). The intensive use of SP pesticides raise environmental concerns (Zhang et al. 2011) because their residues are frequently detected in soils (Han et al. 2017; Liu et al. 2008; Gu et al. 2010) and sediments (Weston et al. 2005; Aznar et al. 2017; Wang et al. 2012; Jabeen et al. 2015), in water (Feng et al. 2015), and even in crops (Akoto et al. 2013; Wahid et al. 2017). SPs can be found in worrying concentrations in terms of toxicity in some non-target invertebrates (Weston et al. 2013; Palmquist et al. 2012). Bifenthrin reached a maximum of $32 \mathrm{ng} \mathrm{g}^{-1}$ in California's Central Valley sediments which is highly toxic compared to an LC50 of 3$10 \mathrm{ng} \mathrm{g}^{-1}$ to common sediment toxicity testing species (Weston et al. 2013). The majority of insecticides reach the soil either by direct application (to kill soil-borne pests) or indirectly when applied to the aerial part of the plant, usually by runoff from the leaves and stems (Farina et al. 2016).

City parks and agricultural soils are often contaminated with metals (Laidlaw et al. 2018; Ponavic et al. 2018; Chen et al. 2018), polycyclic aromatic hydrocarbons ( $\mathrm{Ke}$ et al. 2017), polychlorinated biphenyls ( $\mathrm{Lu}$ and Liu 2015), and pesticides (Li et al. 2008). Contaminated soils should be considered an important source of human pyrethroid exposure namely by dermal contact (as children in playgrounds and farms) or via ingestion of crops cultivated in those soils. From the few studies performed of city park soils, in Beijing, China, the organochlorine pesticides hexachlorocyclohexanes (HCHs) and dichlorodiphenyltrichloroethanes (DDTs) were reported at $0.2490-197.0 \mathrm{ng} \mathrm{g}^{-1}$ and 5.942$1039 \mathrm{ng} \mathrm{g}^{-1}$ concentration levels, respectively ( $\mathrm{Li}$ et al.
2008). For agricultural soils, six pyrethroids (bifenthrin, cypermethrin, cyhalothrin, fenvalerate, fenpropathrin, and deltamethrin) were found in $65.8 \%$ of the investigated nut-planted soils from China, at levels from $1.5 \mathrm{ng} \mathrm{g}^{-1}$ to $884.3 \mathrm{ng} \mathrm{g}^{-1}$ (Han et al. 2017).

Several methods for pyrethroid residue extraction from environmental samples are described in the literature such as Soxhlet extraction (Woudneh and Oros 2006), solid-liquid extraction followed by salting-outassisted liquid-liquid extraction (Pastor-Belda et al. 2018), headspace solid-phase microextraction (Fernandez-Alvarez et al. 2008), microwave-assisted extraction (Esteve-Turrillas et al. 2004), and ultrasound-assisted extraction (Aznar et al. 2017; Albaseer et al. 2010). QuEChERS (Quick Easy Cheap Effective Rugged and Safe) method's numerous advantages are described over the traditional extraction techniques. These include simplicity, low cost, low solvent, and high efficiency with fewer steps (Vera et al. 2013; Fuhrmann et al. 2014). For this reason, QuEChERS was the implemented method in this work for the pyrethroid determination in environmental matrices.

Concerning the increasing use of pyrethroid pesticides worldwide, the present work intended as a major goal the assessment of pyrethroid pesticide soil contamination in Portuguese soils. As described by other authors, a QuEChERS method with gas chromatography (GC) with an electron-capture detector (ECD) was implemented in this work (Dubey et al. 2018). The optimized method for pyrethroid determination was able to quantify trace amounts of eight pyrethroid pesticides (bifenthrin, tetramethrin, cyhalothrin, permethrin, cypermethrin, cyfluthrin, deltamethrin, and fenvalerate) in soils. The efficiency of the methodology was confirmed with ten playground soil samples collected in Porto city and 18 agricultural soils collected in Cávado-Vouga agriculture region. Both types of soils were evaluated for pyrethroid presence and monitored during two seasons (summer and winter).

\section{Materials and Methods}

\subsection{Chemicals and Reagents}

For this study, eight of the most widely used SPs were verified: $\alpha$-cypermethrin, $\beta$-cyfluthrin, -cyhalothrin, bifenthrin, deltamethrin, fenvalerate, permethrin, and tetramethrin. Pesticide standards (more than $95.4 \%$ of 
purity) were purchased from Chemservice (West Chester, USA) and Sigma-Aldrich Co. Merck was the supplier of the acetonitrile and $n$-hexane (high-purity solvents). Individual pesticide standard stock solutions (between 100 and $200 \mathrm{mg} \mathrm{L}^{-1}$ ) were prepared in acetonitrile. Standard working solutions (with the eight SPs) were prepared from individual stock solutions at several concentrations' levels. Stock and working solutions were stored at $4{ }^{\circ} \mathrm{C}$. Agilent technologies (Bond Elut Sample preparation solutions; Lake Forest, USA) was the supplier of QuEChERS and the dSPE. The QuEChERS used was a buffer-salt mixture with $4 \mathrm{~g}$ of magnesium sulfate anhydrous grit $\left(\mathrm{MgSO}_{4}\right), 1 \mathrm{~g}$ of sodium chloride $(\mathrm{NaCl}), 0.5 \mathrm{~g}$ of sodium hydrogenocitrate sesquihydrate $\left(\mathrm{C}_{6} \mathrm{H}_{8} \mathrm{Na}_{2} \mathrm{O}_{8}\right)$, and $1 \mathrm{~g}$ of sodium citrate $\left(\mathrm{Na}_{3} \mathrm{C}_{6} \mathrm{H}_{5} \mathrm{O}_{7}\right)$. The dSPE was composed of 150-mg primary secondary amine (PSA), 150$\mathrm{mg} \mathrm{MgSO}_{4}$, and 50-mg bonded silica (C18). Deionized water was obtained and purified $(18.2 \mathrm{M} \Omega \mathrm{cm})$ using water purification systems from Millipore (Elix apparatus and a Simplicity 185 system). Helium (purity $\geq$ 99.999\%) and nitrogen (purity $\geq 99.999 \%$ ) were both obtained from Linde Sogás (Lisbon, Portugal).

\subsection{Study Area and Sample Collection}

Different topsoil samples were collected from several urban playground parks (P1-P10) and agricultural locations (A1-A18) of the north of Portugal. The upper layer (topsoil, $0-10 \mathrm{~cm}$ ) was removed with a clean spade from each sampling site. Different sampling points, with similar characteristics, of the playground park and agricultural soil were collected in order to have a representative sample of the area to obtain a composite sample. Samples were sieved $(2 \mathrm{~mm})$ and were stored at $-18{ }^{\circ} \mathrm{C}$ until analysis.

\subsubsection{Playground Soils}

The sampling was done in playgrounds of urban areas of the north of Portugal, in Porto city and surrounding regions. The playgrounds selected were the ones set in city parks with a high density of green areas, with several different types of trees (e.g., pines, Metrosideros, palm, and cork trees), grass areas, shrubs, camellia gardens, and rosebushes. Dogs are allowed in these parks. Ten soil samples were taken at various locations in Porto city, on the 5th and 6th of September 2015 (summer) and 20th and 21st of February 2016 (winter) (Fig. 1).

\subsubsection{Agricultural Soils}

The farming sampling sites were in the agricultural regional delegation of Cávado-Vouga. Eighteen soil samples were collected during the first week of July 2016 (summer) and the first week of January 2017 (winter) at the marked sites (Fig. 2). The samples were all coming from conventional agriculture soils. Five of them were from intensive farming practices (A1, A2, $\mathrm{A} 7, \mathrm{~A} 15$, and A18) and the remaining ones were from sustainable agriculture practices.

\subsection{Soil Analysis and Characterization}

The physicochemical characterization of soils was performed, namely the $\mathrm{pH}$, the water content, and the total organic carbon (TOC) (Nelson 1996; Hesse 1972), and was determined. For the analysis of TOC in soils, a Shimadzu TOC analyzer (VCSN, Japan) and a Shimadzu solid sample module (SSM-5000A) were used. A Kern moisture analyzer (MLS 50-3IR160, Germany) was used to determine the water content. For the measure of the $\mathrm{pH}$, a suspension of soil in water (1:1) was read with an electronic $\mathrm{pH}$ meter (Crison 2002, Spain). All determinations were made in triplicate.

\subsubsection{QuEChERS Extraction Procedure}

Soils were extracted using an adapted QuEChERS method from the European (EN15662 2008) method (EN15662 2008; Dubey et al. 2018). As described before by others authors, a smaller amount of sample $(5 \mathrm{~g})$ was used that was weighed into a Teflon tube $(50 \mathrm{~mL})$ to which $10 \mathrm{~mL}$ of acetonitrile was added (Correia-Sá et al. 2012; Bragança et al. 2012). The tube was capped, shacked vigorously by vortexing for $1 \mathrm{~min}$, and sonicated $(10 \mathrm{~min})$ in a 195-W ultrasonic bath from J.P. Selecta (Spain). The QuEChERS buffer-salt mixture was then added to the suspension resultant from this extraction. Phase separation and pesticide partitioning were induced by shaking vigorously for $1 \mathrm{~min}$ in a vortex, followed by placing in an ultrasonic bath for $10 \mathrm{~min}$ and later centrifugation at $4000 \mathrm{rpm}(10 \mathrm{~min})$. A $1.5-\mathrm{mL}$ aliquot was sampled from the upper layer and 


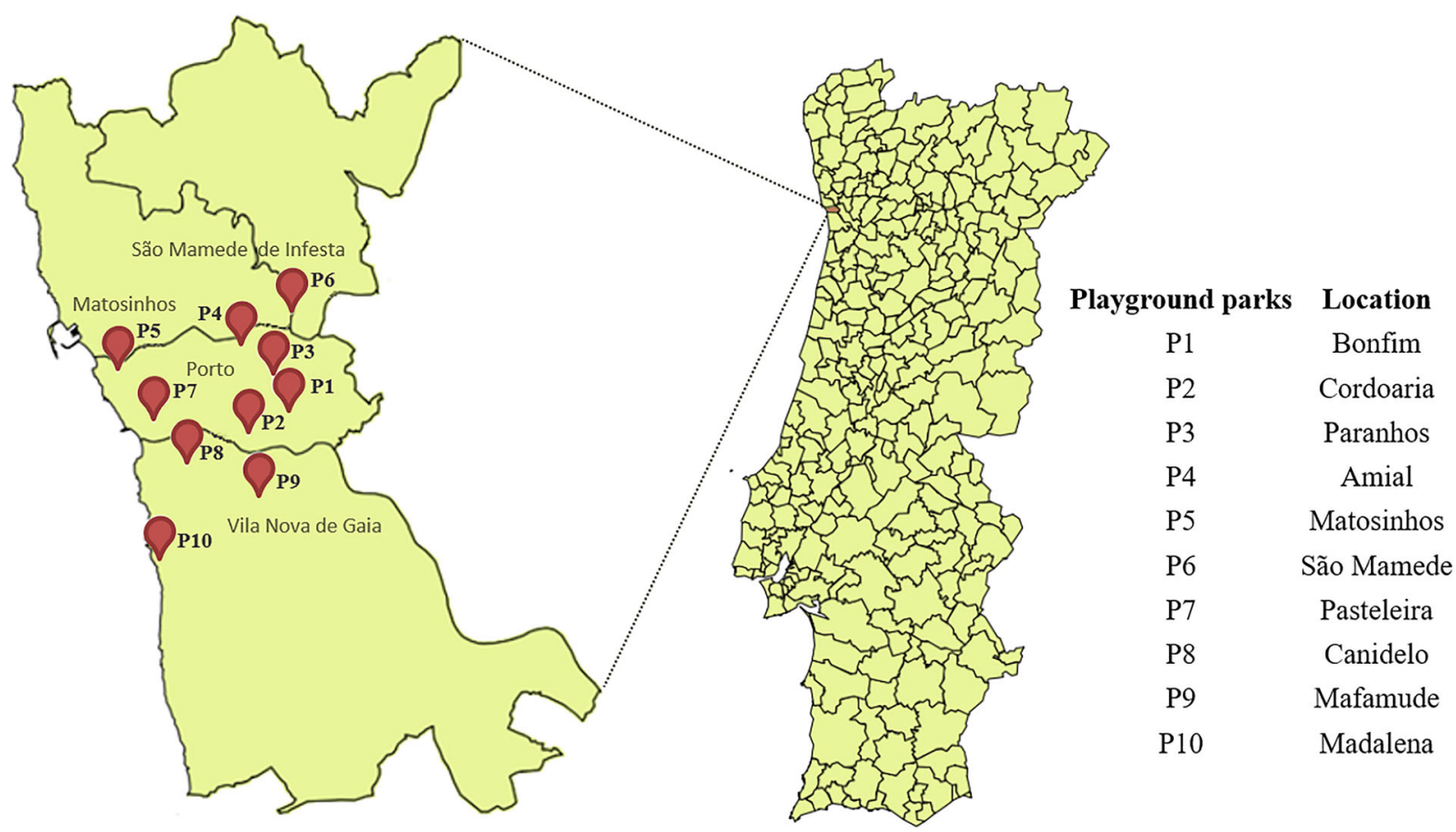

Fig. 1 Location map of playgrounds sampling sites (P1-P10)

moved into a 2-mL cleanup tube, vortexed for $1 \mathrm{~min}$, and centrifuged at $4000 \mathrm{rpm}(10 \mathrm{~min})$. A $0.7-\mathrm{mL}$ aliquot of the upper layer was removed into a vial and evaporated with a nitrogen gentle stream until dryness. The dry residue was resuspended in $0.7 \mathrm{~mL}$ of $n$-hexane and vortex-shacked vigorously, and finally the extract was analyzed by GC-ECD chromatograph.

\subsubsection{Gas Chromatography}

SPs were analyzed using a GC-ECD (Shimadzu GC2010) with a capillary column ZB-XLB (30 m length, $0.25 \mathrm{~mm}$ i.d., $0.25 \mathrm{~mm}$ film thickness; Zebron - Phenomenex). The temperature of the oven was set to start at $60^{\circ} \mathrm{C}$ (stay for $1 \mathrm{~min}$ ), increase by $30{ }^{\circ} \mathrm{C} \mathrm{min}{ }^{-1}$ till $250{ }^{\circ} \mathrm{C}$ (held for $11 \mathrm{~min}$ ), and then an increase of $10^{\circ} \mathrm{C} \min ^{-1}$ till $290{ }^{\circ} \mathrm{C}$. The injection port was operated at $250{ }^{\circ} \mathrm{C}$ (in splitless mode) and the detector was set at $300{ }^{\circ} \mathrm{C}$. Injection $(1 \mu \mathrm{L})$ was carried out with an autosampler (HT 300A from hta). Helium was used as the carrier gas (1.5 $\left.\mathrm{mL} \mathrm{min}^{-1}\right)$, while nitrogen was the makeup

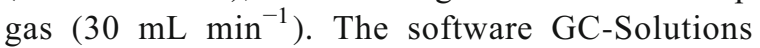
Shimadzu was used for sample processing.
In addition, the samples positive to deltamethrin were further analyzed using a Zebron ZB-5MSi column (30 m length, $0.25 \mathrm{~mm}$ i.d., $0.25 \mu \mathrm{m}$ film thickness; Phenomenex) in a Thermo Trace-Ultra gas chromatography-mass spectrometry Thermo Polaris Q ion trap detector operated in the electronimpact ionization (EI) at $70 \mathrm{eV}$. Injection $(1 \mu \mathrm{L})$ was carried out with an autosampler (AI3000) in an injector set at $240{ }^{\circ} \mathrm{C}$ (splitless mode). Helium was used as the carrier gas $\left(1 \mathrm{~mL} \mathrm{~min}^{-1}\right)$. The temperature of the oven was programmed to start at $90{ }^{\circ} \mathrm{C}$ (held for $1 \mathrm{~min}$ ), followed by an increase of $15{ }^{\circ} \mathrm{C} / \mathrm{min}$ to $250{ }^{\circ} \mathrm{C}$ (held for $1 \mathrm{~min}$ ), then an increase of $20{ }^{\circ} \mathrm{C} / \mathrm{min}$ to $255{ }^{\circ} \mathrm{C}$ (held for $5 \mathrm{~min}$ ), a new increase of $10{ }^{\circ} \mathrm{C} / \mathrm{min}$ till $270{ }^{\circ} \mathrm{C}$ (held for $1 \mathrm{~min}$ ), and finally an increase of $20{ }^{\circ} \mathrm{C} / \mathrm{min}$ to $290{ }^{\circ} \mathrm{C}$ (stay for $2 \mathrm{~min}$ ). The transfer line temperature was $270{ }^{\circ} \mathrm{C}$ and the ion source temperature was $250{ }^{\circ} \mathrm{C}$. The MS/MS conditions were as follows: maximum excitation energy of 0.225 , excitation voltage of $0.5 \mathrm{~V}$, excitation time of $15 \mathrm{~ms}$, isolation mass window width of 1.0 , and isolation time of $12 \mathrm{~ms}$. The identification of the selected precursor ion for deltamethrin was 172 as it was the one with the maximum abundance factor and $\mathrm{m} / \mathrm{z}$ ratio. The software Xcalibur 1.3 was used for data processing. 


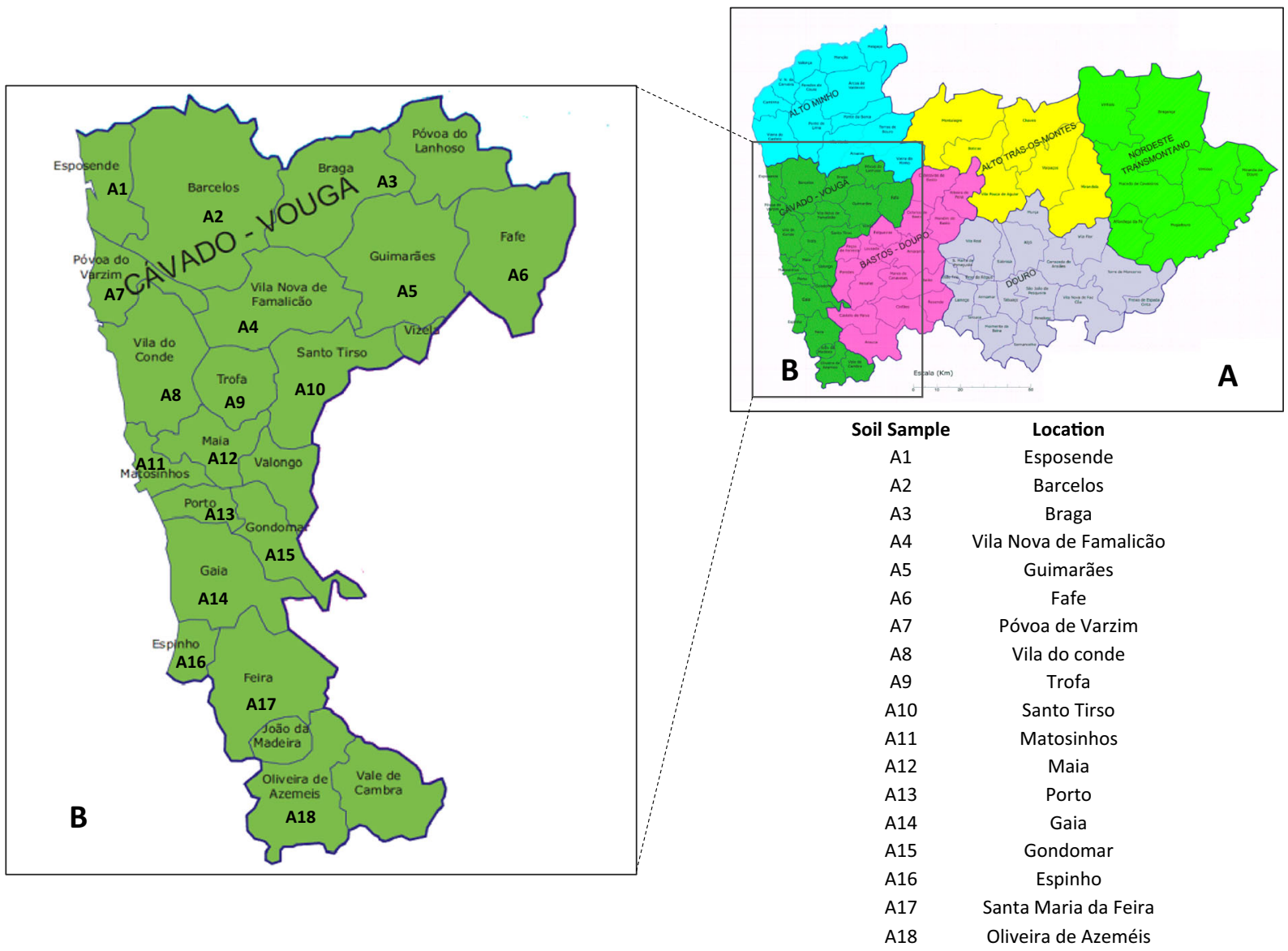

Fig. 2 Map of agricultural soil sampling locations (A1-A18). A, Agriculture regional delegations of the north of Portugal; B, Agriculture regional delegation of Cávado-Vouga

\subsection{Method Validation}

For SP analysis, the experimental method validation was performed according to the SANCO guidelines from the European Union, regarding pesticide residue analytical methods (EU 2010, 2013). The matrix effect influence on the ECD signal was evaluated by setting up a calibration curve using soil extract and comparing with the one achieved for the standards in hexane. SPs' calibration curves and linear range response were evaluated through the analysis of eight standard solutions (10 to $360 \mathrm{ng} \mathrm{g}^{-1}$ ) in triplicate. The organic carbon content (OC) produces a matrix effect on the QuEChERS method (Correia-Sá et al. 2012). To ascertain this effect, two calibration curves were performed: one for a soil with a low TOC content $(0.374 \%)$ and another for a soil with high TOC content $(\mathrm{OC}=3.70 \%)$. The detection and quantification limits (LODs and LOQs) were determined using the standard deviation (SD) of the response (SD of $y$-intercepts of the regression lines), the slope of the calibration curve, and the signal-to-noise ratio convention, 3:1 for LODs and 10:1 for LOQs (Rambla-Alegre et al. 2012). The linearity of the method was established by setting calibration curves over the concentration range using linear regression analysis. Selectivity was verified by comparing the chromatograms of standards dissolved in $n$-hexane, standards extracted from the spiked soil, and matrix blanks (nonspiked soil). The precision of the method was evaluated by carrying out the extraction and analysis of 40,200 , and $360 \mathrm{ng} \mathrm{g}^{-1}$ fortified samples using three replicates, being the extract injected in triplicate. The analytical method of accuracy was evaluated through recovery studies (EU 2010, 2013). 


\section{Results and Discussion}

\subsection{Soil Sample Characterization}

The $\mathrm{pH}$ values were similar for both types of soil and for both seasons (Table 1). It was noted that for both types of soils, the water content was lower in summer than in winter with much higher rainfalls, in accordance with the climatic conditions of each season. The determination of TOC was an important part of soil characterization since its presence/absence could affect how chemicals would respond in the soil (Correia-Sá et al. 2012). TOC contents in agricultural soils (1.24-7.02\%) were generally higher than those in playgrounds soils $(0.03-2.87 \%)$.

\subsection{Method Performance and Validation}

Since some authors reported an influence of the amount of organic carbon on the matrix effect, soils with different TOC contents were tested (Correia-Sá et al. 2012). Considering different total organic carbon contents, comparing the two matrix calibration curves (low and higher TOC content), no matrix effect was observed in all compounds (data not shown). As such, the calibration curves were constructed with fortified extracts using the soil with low TOC content. The chromatograms obtained for extracts with pyrethroid after the QuEChERS method application are shown in Fig. S1, comparing the non-spiked soil (matrix blank), the standards dissolved in $n$-hexane, and the spiked soil. The QuEChERS method provided extracts that contained the target analyte, with high recoveries, and free from interferences in terms of the pesticide's retention time.

Analytical parameters for method performance and validation were calculated for the applied method to each pyrethroid pesticide and are reported in Table 2. Method accuracy was expressed as recovery from the fortified blank soil samples at 40, 200, and $360 \mathrm{ng} / \mathrm{g}$ concentration levels, with good recoveries (79.4$100.2 \%$ ), and with precision values, as determined by the mean of the relative standard deviation (RSD), below $9.5 \%$ in all cases. These determinations comply with the requirement guidelines of the European Commission concerning methods of analyzing pesticide residues (EU 2013). Linear calibration curves for all the investigated pesticides were obtained in the range of 10 and $360 \mathrm{ng} \mathrm{g}^{-1}$ with coefficients of determination higher than 0.991 . The limits of detection and quantification ranged from 0.33 to $2.72 \mathrm{ng} \mathrm{g}^{-1}$ and $1.10 \mathrm{ng} \mathrm{g}^{-1}$ to $9.06 \mathrm{ng} \mathrm{g}^{-1}$, respectively.

\subsection{Pyrethroid in Soils}

Eight pyrethroid pesticides (i.e., bifenthrin, deltamethrin, cyhalothrin, cyfluthrin, cypermethrin, fenvalerate, permethrin, and tetramethrin) were analyzed in playgrounds and agricultural soils. When the validated procedure for the monitoring of pyrethroid pesticide residues was applied to the ten nonspiked soil samples from Porto city playgrounds, no pyrethroid contamination was found (not detected) during both seasons. Considering the potential effect of pyrethroids by dermal contact (Hołyńska-Iwan et al. 2018), these city playgrounds may be considered safe for children. Since the understanding of the environmental quality and the impact of these compounds in daily life is crucial future analyses in a wider territory, a higher number of samples and including more pyrethroid compounds are of major importance as these urban facilities are frequently visited. Also, playground air contamination with pyrethroid residues should be considered.

Table 3 contains the results of the pyrethroid contamination detected in agricultural soils. Deltamethrin was the only pyrethroid pesticide confirmed by GC-MS/MS, out of the eight analyzed. It was detected in three of the 18 agricultural soils only during the summer period, while in the winter, no pyrethroid contamination was found. The occurrence only happening in summer may be related to their usage pattern, since pesticides are usually applied in the spring/summer, as advised by the Ministry of Agriculture Forestry and Rural Development (DGAV n.d.). Many pyrethroids undergo microbial biodegradation by the action of several esterases, justifying that SPs were not detected in winter. When pyrethroids were present in measurable amounts, their concentrations were $15.7,17.8$, and $101.7 \mathrm{ng} \mathrm{g}^{-1}$ for samples A18, A8, and A5, respectively. No relation between the type of agriculture practices and the presence of pyrethroid pesticides was found since A18 was a soil sample from intensive farming and while the other positive soil samples were from sustainable agriculture practices. Comparing with available literature, six SPs (bifenthrin, fenpropathrin, cyhalothrin, cypermethrin, fenvalerate, and deltamethrin) were 
Table 1 Macro parameters of soil samples. Characterization mean values with standard deviation (SD)

\begin{tabular}{|c|c|c|c|c|c|c|}
\hline \multirow[t]{2}{*}{ Soil sample } & \multicolumn{2}{|l|}{$\mathrm{pH}$} & \multicolumn{2}{|c|}{ Water content $(\%)$} & \multicolumn{2}{|c|}{ Total organic carbon (\%) } \\
\hline & Summer & Winter & Summer & Winter & Summer & Winter \\
\hline \multicolumn{7}{|c|}{ Playground soils } \\
\hline $\mathrm{P} 1$ & $7.20(0.05)$ & $7.55(0.06)$ & $1.10(0.12)$ & $10.11(0.84)$ & $0.65(0.04)$ & $0.27(0.03)$ \\
\hline $\mathrm{P} 2$ & $7.16(0.11)$ & $6.95(0.09)$ & $9.18(0.32)$ & $3.86(0.61)$ & $1.61(0.20)$ & $0.08(0.01)$ \\
\hline P3 & $6.31(0.09)$ & $5.84(0.01)$ & $12.54(0.22)$ & $23.99(0.42)$ & $2.87(0.39)$ & $2.65(0.15)$ \\
\hline $\mathrm{P} 4$ & $6.31(0.09)$ & $7.53(0.02)$ & $4.64(0.34)$ & $4.23(0.25)$ & $0.63(0.06)$ & $0.91(0.11)$ \\
\hline P5 & $8.52(0.27)$ & $8.51(0.07)$ & $3.61(0.14)$ & $2.88(0.27)$ & $0.10(0.01)$ & $0.14(0.01)$ \\
\hline P6 & $6.87(0.14)$ & $7.52(0.11)$ & $1.98(0.05)$ & $2.45(0.19)$ & $0.22(0.01)$ & $0.03(0.01)$ \\
\hline $\mathrm{P} 7$ & $6.33(0.08)$ & $6.85(0.03)$ & $0.94(0.07)$ & $3.03(0.28)$ & $0.13(0.03)$ & $0.14(0.01)$ \\
\hline P8 & $5.70(0.06)$ & $6.33(0.08)$ & $8.86(0.22)$ & $15.93(0.26)$ & $0.22(0.01)$ & $0.22(0.01)$ \\
\hline P9 & $5.59(0.06)$ & $5.17(0.18)$ & $5.63(0.07)$ & $12.35(1.15)$ & $1.90(0.25)$ & $1.40(0.15)$ \\
\hline $\mathrm{P} 10$ & $7.80(0.17)$ & $7.96(0.16)$ & $5.89(0.12)$ & $8.35(0.61)$ & $0.31(0.03)$ & $0.16(0.01)$ \\
\hline \multicolumn{7}{|c|}{ Agricultural soils } \\
\hline A1 & $5.65(0.09)$ & $6.33(0.04)$ & $14.93(0.21)$ & $24.98(0.29)$ & $2.79(0.05)$ & $2.64(0.08)$ \\
\hline A2 & $5.71(0.03)$ & $5.73(0.10)$ & $13.25(0.09)$ & $20.35(0.04)$ & $3.15(0.24)$ & $2.72(0.20)$ \\
\hline A3 & $5.51(0.02)$ & $5.91(0.02)$ & $16.78(0.09)$ & $18.83(0.00)$ & $2.30(0.26)$ & $2.27(0.06)$ \\
\hline A4 & $5.39(0.07)$ & $5.73(0.01)$ & $19.33(0.16)$ & $26.33(0.19)$ & $3.80(0.08)$ & $2.87(0.02)$ \\
\hline A5 & $7.03(0.11)$ & $6.63(0.08)$ & $9.46(0.37)$ & $18.24(0.30)$ & $1.24(0.06)$ & $1.41(0.08)$ \\
\hline A6 & $5.42(0.07)$ & $6.04(0.13)$ & $17.76(0.60)$ & $23.45(0.05)$ & $2.36(0.04)$ & $1.97(0.06)$ \\
\hline A7 & $5.86(0.07)$ & $5.53(0.03)$ & $14.31(0.04)$ & $22.93(0.56)$ & $3.98(0.34)$ & $3.43(0.02)$ \\
\hline A8 & $6.97(0.05)$ & $6.76(0.12)$ & $21.96(2.28)$ & $24.51(0.18)$ & $5.70(0.08)$ & $5.28(0.00)$ \\
\hline A9 & $5.91(0.12)$ & $6.10(0.16)$ & $9.96(0.38)$ & $6.82(0.32)$ & $1.59(0.10)$ & $2.12(0.08)$ \\
\hline A10 & $6.91(0.00)$ & $6.55(0.15)$ & $9.04(0.01)$ & $18.94(0.03)$ & $3.45(0.51)$ & $2.76(0.11)$ \\
\hline A11 & $6.68(0.00)$ & $6.45(0.04)$ & $19.18(0.42)$ & $22.20(0.16)$ & $3.12(0.11)$ & $3.21(0.05)$ \\
\hline A12 & $6.76(0.00)$ & $6.19(0.01)$ & $15.41(0.47)$ & $23.14(0.36)$ & $3.87(0.23)$ & $3.11(0.24)$ \\
\hline A13 & $6.64(0.14)$ & $6.86(0.12)$ & $19.00(0.65)$ & $19.96(0.25)$ & $5.91(0.55)$ & $5.34(0.37)$ \\
\hline A14 & $4.52(0.05)$ & $6.52(0.09)$ & $17.22(0.20)$ & $8.03(0.10)$ & $1.82(0.13)$ & $2.51(0.14)$ \\
\hline A15 & $6.72(0.10)$ & $6.46(0.01)$ & $25.57(3.65)$ & $29.48(0.03)$ & $4.90(0.12)$ & $7.02(0.28)$ \\
\hline A16 & $6.96(0.04)$ & $6.39(0.01)$ & $2.77(0.08)$ & $30.03(0.33)$ & $3.20(0.11)$ & $3.82(0.17)$ \\
\hline A17 & $6.77(0.02)$ & $6.93(0.08)$ & $1.70(0.32)$ & $12.95(0.03)$ & $1.32(0.04)$ & $2.54(0.25)$ \\
\hline A18 & $6.59(0.03)$ & $7.41(0.04)$ & $17.73(0.03)$ & $22.67(0.00)$ & $2.25(0.27)$ & $2.66(0.03)$ \\
\hline
\end{tabular}

found in chestnut, walnut, and pine soils in China (29.4 $\mathrm{ng} \mathrm{g}^{-1}$ to $884.3 \mathrm{ng} \mathrm{g}^{-1}, 9.7 \mathrm{ng} \mathrm{g}^{-1}$ to $57.3 \mathrm{ng} \mathrm{g}^{-1}$, and $1.5 \mathrm{ng} \mathrm{g}^{-1}$ to $85.0 \mathrm{ng} \mathrm{g}^{-1}$, respectively) (Han et al. 2017). Creeks sediments collected inside a residential neighborhood near Roseville (USA) presented maximum concentrations of 169 , 335,437 , and $736 \mathrm{ng} \mathrm{g}^{-1}$ of cyfluthrin, permethrin, bifenthrin, and cypermethrin, respectively (Weston et al. 2005). Several SPs (bifenthrin, cyhalothrin, cyfluthrin, cypermethrin, deltamethrin, fenpropathrin, fluvalinate, permethrin, esfenvalerate, and resmethrin) were also detected in the Mediterranean paddy fields at a maximum concentration of $57.0 \mathrm{ng} \mathrm{g}^{-1}$ before plow and $62.3 \mathrm{ng} \mathrm{g}^{-1}$ during rice production, being resmethrin and cyfluthrin the compounds detected at higher concentrations (Aznar et al. 2017). Deltamethrin was also found in other reports. For instance, in a chestnut soil in China, deltamethrin varied between n.d and $29.3 \mathrm{ng} \mathrm{g}^{-1}$ (Han et al. 2017). Considering their presence in crops, in Ejura, Ghana, nine pyrethroids (bifenthrin, fenpropathrin, cyhalothrin, permethrin, 
Table 2 Recoveries, detection and quantification limits (LOD, LOQ), and matrix effect for the investigated compounds

\begin{tabular}{llllllll}
\hline Compound & \multicolumn{2}{l}{ Recoveries, \% (RSD, \%) } & LOD & \multicolumn{2}{l}{ LOQ } & \multicolumn{2}{c}{$\begin{array}{c}\text { Determination coefficient } \\
\text { Matrix effect }(\%)\end{array}$} \\
\cline { 2 - 6 } & $40 \mathrm{ng} \mathrm{g}^{-1}$ & $200 \mathrm{ng} \mathrm{g}^{-1}$ & $360 \mathrm{ng} \mathrm{g}^{-1}$ & $\left(\mathrm{ng} \mathrm{g}^{-1}\right)$ & $\left(\mathrm{ng} \mathrm{g}^{-1}\right)$ & $\left(r^{2}\right)$ & -3.6 \\
\hline Bifenthrin & $92.8(6.8)$ & $93.0(6.5)$ & $80.5(6.2)$ & 1.73 & 5.78 & 0.991 & 5.3 \\
Tetramethrin & $85.0(8.4)$ & $92.5(5.6)$ & $78.8(6.9)$ & 1.29 & 4.28 & 0.991 & 8.1 \\
Cyhalothrin & $79.9(9.3)$ & $92.2(6.4)$ & $79.4(1.2)$ & 2.72 & 9.06 & 0.994 & 3.5 \\
Permethrin & $87.6(9.5)$ & $92.5(6.7)$ & $81.2(2.0)$ & 2.34 & 7.79 & 0.991 & 12.8 \\
Cyfluthrin & $89.1(8.5)$ & $99.2(7.2)$ & $80.4(4.4)$ & 1.97 & 6.56 & 0.997 & 10.6 \\
Cypermethrin & $83.7(8.0)$ & $95.3(7.0)$ & $85.3(3.0)$ & 2.50 & 8.32 & 0.997 & 11.2 \\
Fenvalerate & $81.8(9.1)$ & $95.2(7.9)$ & $81.2(2.2)$ & 0.33 & 1.10 & 0.998 & 33.1 \\
Deltamethrin & $84.7(7.8)$ & $100.2(7.2)$ & $81.2(1.1)$ & 0.85 & 2.83 & 0.997 & \\
\hline
\end{tabular}

cyfluthrin, cypermethrin, fenvalerate, allethrin, and deltamethrin) were detected in all cowpea-and maize-measured samples, with average concentrations from 1 to $39 \mathrm{ng} \mathrm{g}^{-1}$ and from 2 to $28 \mathrm{ng} \mathrm{g}^{-1}$, respectively. In particular, with deltamethrin, the detected levels ranged from 3 to $13 \mathrm{ng} \mathrm{g}^{-1}$ (cowpea) and from 2 to $3 \mathrm{ng} \mathrm{g}^{-1}$ (maize) (Akoto et al. 2013).

Table 3 Concentrations (ng $\mathrm{g}^{-1}$ ) of deltamethrin in agricultural soils from the north of Portugal

\begin{tabular}{lll}
\hline Soil sample & \multicolumn{2}{l}{ Deltamethrin $\left(\mathrm{ng} \mathrm{g}^{-1}\right)$} \\
\cline { 2 - 3 } & Summer & \\
\hline A1 & n.d & Winter \\
A2 & n.d & n.d \\
A3 & n.d & n.d \\
A4 & n.d & n.d \\
A5 & $101.7 \pm 7.2$ & n.d \\
A6 & n.d & n.d \\
A7 & n.d & n.d \\
A8 & $17.8 \pm 0.2$ & n.d \\
A9 & n.d & n.d \\
A10 & n.d & n.d \\
A11 & n.d & n.d \\
A12 & n.d & n.d \\
A13 & n.d & n.d \\
A14 & n.d & n.d \\
A15 & n.d & n.d \\
A16 & n.d & n.d \\
A17 & n.d & n.d \\
A18 & $15.7 \pm 0.7$ & n.d \\
\hline & & \\
\hline
\end{tabular}

\section{Conclusions}

The intensive use of pyrethroid pesticides raises environmental concerns, especially regarding soil contamination. The spatial and seasonal occurrence of pyrethroid pesticide contaminants in the environment was the focus of this work. The methodology implemented for pyrethroid analysis could be extremely relevant for further studies related to pyrethroid exposition and its effects. No evidence was found that, in Portuguese playground soil samples, the pyrethroid pesticides analyzed were present. Nevertheless, $17 \%$ of the agricultural soil samples tested had measurable levels for one target pyrethroid (deltamethrin) during the summer season. The results confirm the presence of pyrethroid pesticides in Portuguese soils and the need for monitoring and assessment. In order to circumvent this problem, tests should be done in a wider territory, with a higher number of samples and including more pyrethroid compounds, both in urban and rural facilities. A deeper understanding of the environmental and the ecological potential impacts of pyrethroid pesticides in soil is needed.

Acknowledgments I. Bragança is grateful to FCT for the doctoral research grant financed by fellowship (SFRH/BD/52504/ 2014). Paulo C. Lemos acknowledges the support by FCT/ MCES for contract IF/01054/2014. The authors are greatly indebted to all financing sources.

Funding Information This work was supported by the Associate Laboratory for Green Chemistry - LAQV which is financed by the national funds from FCT/MCTES (UID/QUI/50006/2013) and co-financed by the ERDF under the PT2020 Partnership Agreement (POCI-01-0145-FEDER - 007265). 


\section{References}

Akoto, O., Andoh, H., Darko, G., Eshun, K., \& Osei-Fosu, P. (2013). Health risk assessment of pesticides residue in maize and cowpea from Ejura, Ghana. Chemosphere, 92(1), 67-73. https://doi.org/10.1016/j.chemosphere.2013.02.057.

Albaseer, S. S., Nageswara Rao, R., Swamy, Y. V., \& Mukkanti, K. (2010). An overview of sample preparation and extraction of synthetic pyrethroids from water, sediment and soil. Journal of Chromatography A, 1217(35), 5537-5554. https://doi.org/10.1016/j.chroma.2010.06.058.

Albaseer, S. S., Rao, R. N., Swamy, Y. V., \& Mukkanti, K. (2011). Analytical artifacts, sample handling and preservation methods of environmental samples of synthetic pyrethroids. Trac-Trends in Analytical Chemistry, 30(11), 1771-1780. https://doi.org/10.1016/j.trac.2011.05.010.

Aznar, R., Moreno-Ramon, H., Albero, B., Sanchez-Brunete, C., \& Tadeo, J. L. (2017). Spatio-temporal distribution of pyrethroids in soil in Mediterranean paddy fields. Journal of Soils and Sediments, 17(5), 1503-1513. https://doi.org/10.1007 /s11368-016-1417-2.

Bragança, I., Plácido, A., Paíga, P., Domingues, V. F., \& DelerueMatos, C. (2012). QuEChERS: a new sample preparation approach for the determination of ibuprofen and its metabolites in soils. [article]. Science of the Total Environment, 433, 281-289. https://doi.org/10.1016/j.scitotenv.2012.06.035.

Burns, C. J., \& Pastoor, T. P. (2018). Pyrethroid epidemiology: a quality-based review. Critical Reviews in Toxicology, 48(4), 297-311. https://doi.org/10.1080/10408444.2017.1423463.

Chen, S., Gu, S., Wang, Y., Yao, Y., Wang, G., Jin, Y., et al. (2016). Exposure to pyrethroid pesticides and the risk of childhood brain tumors in East China. Environmental Pollution, 218, 1128-1134. https://doi.org/10.1016/j.envpol.2016.08.066.

Chen, Y. N., Zhang, J. Q., Zhang, F., Liu, X. P., \& Zhou, M. (2018). Contamination and health risk assessment of PAHs in farmland soils of the Yinma River basin, China. Ecotoxicology and Environmental Safety, 156, 383-390. https://doi.org/10.1016/j.ecoenv.2018.03.020.

Correia-Sá, L., Fernandes, V. C., Carvalho, M., Calhau, C., Domingues, V. F., \& Delerue-Matos, C. (2012). Optimization of QuEChERS method for the analysis of organochlorine pesticides in soils with diverse organic matter. Journal of Separation Science, 35(12), 1521-1530. https://doi.org/10.1002/jssc.201200087.

DGAV (n.d.). Serviço Nacional Avisos Agrícolas. http://snaa. dgav.pt/. Accessed 13 Aug 2018.

Domingues, V. F., Nasuti, C., Piangerelli, M., Correia-Sa, L., Ghezzo, A., Marini, M., et al. (2016). Pyrethroid pesticide metabolite in urine and microelements in hair of children affected by autism spectrum disorders: a preliminary investigation. International Journal of Environmental Research and Public Health, 13(4), 388.

Dubey, J. K., Patyal, S. K., \& Sharma, A. (2018). Validation of QuEChERS analytical technique for organochlorines and synthetic pyrethroids in fruits and vegetables using GCECD. Environmental Monitoring and Assessment, 190(4). https://doi.org/10.1007/s10661-018-6584-8.

EN15662 (2008). Foods of plant origin - determination of pesticide residues using GC-MS and/or LC-MS/MS following acetonitrile extraction/partitioning and clean-up by dispersive SPE-QuEChERS. (Vol. EN 15662).

Esteve-Turrillas, F. A., Aman, C. S., Pastor, A., \& de la Guardia, M. (2004). Microwave-assisted extraction of pyrethroid insecticides from soil. Analytica Chimica Acta, 522(1), 73-78. https://doi.org/10.1016/j.aca.2004.06.039.

European Union (2010). Guidance document on pesticide residue analytical methods. European Commision, Directorate General Health and ConsumerProtection.

European Committee for Standardization (2018). EN 15662 Foods of plant origin - Multimethod for the determination of pesticide residues using GC- and LC-based analysis following acetonitrile extraction/partitioning and clean-up by dispersive SPE - Modular QuEChERS-method.

EU (2013). Guidance document on analytical quality control and validation procedures for pesticide residues analysis in food and feed. (Vol. SANCO/12571/2013): European commission, Health \& consumer protection directorate-general.

Farina, Y., Abdullah, P. B., \& Bibi, N. (2016). Extraction procedures in gas chromatographic determination of pesticides. Journal of Analytical Chemistry, 71(4), 339-350. https://doi.org/10.1134/S1061934816040092.

Feng, L., Yang, G., Zhu, L., Xu, J., Xu, X., \& Chen, Y. (2015). Distribution and risk assessment of endocrine-disrupting pesticides in drinking water sources from agricultural watershed. Water, Air, \& Soil Pollution, 227(1), 23. https://doi. org/10.1007/s11270-015-2704-z.

Fernandez-Alvarez, M., Llompart, M., Lamas, J. P., Lores, M., Garcia-Jares, C., Cela, R., et al. (2008). Simultaneous determination of traces of pyrethroids, organochlorines and other main plant protection agents in agricultural soils by headspace solid-phase microextraction-gas chromatography. Journal of Chromatography A, 1188(2), 154-163. https://doi.org/10.1016/j.chroma.2008.02.080.

Fuhrmann, A., Gans, O., Weiss, S., Haberhauer, G., \& Gerzabek, M. H. (2014). Determination of bentazone, chloridazon and terbuthylazine and some of their metabolites in complex environmental matrices by liquid chromatographyelectrospray ionization-tandem mass spectrometry using a modified QuEChERS method: an optimization and validation study. Water, Air, \& Soil Pollution, 225(5), 1944. https://doi.org/10.1007/s11270-014-1944-7.

Gu, X.-Z., Zhang, L., Zhang, G.-y., Fan, C.-X., \& Chen, L. (2010). Preliminary evidence that copper and zinc inhibits the dissipation of synthetic pyrethroid in red soil. Water, Air, \& Soil Pollution, 212(1), 345-355. https://doi.org/10.1007/s11270010-0348-6.

Han, Y., Mo, R., Yuan, X., Zhong, D., Tang, F., Ye, C., et al. (2017). Pesticide residues in nut-planted soils of China and their relationship between nut/soil. Chemosphere, 180, 4247. https://doi.org/10.1016/j.chemosphere.2017.03.138.

Hesse, P. R. (Ed.). (1972). A textbook of soil chemical analysis. New York: Chemical Publishing Co., Inc..

Hołyńska-Iwan, I., Bogusiewicz, J., Chajdas, D., SzewczykGolec, K., Lampka, M., \& Olszewska-Słonina, D. (2018). The immediate influence of deltamethrin on ion transport through rabbit skin. An in vitro study. Pesticide Biochemistry and Physiology, 148, 144-150. https://doi. org/10.1016/j.pestbp.2018.04.011.

Jabeen, F., Chaudhry, A. S., Manzoor, S., \& Shaheen, T. (2015). Examining pyrethroids, carbamates and neonicotenoids in 
fish, water and sediments from the Indus River for potential health risks. Environmental Monitoring and Assessment, 187(2), 29. https://doi.org/10.1007/s10661-015-4273-4.

Ke, C. L., Gu, Y. G., \& Liu, Q. (2017). Polycyclic aromatic hydrocarbons (PAHs) in exposed-lawn soils from 28 urban parks in the megacity Guangzhou: occurrence, sources, and human health implications. Archives of Environmental Contamination and Toxicology, 72(4), 496-504. https://doi. org/10.1007/s00244-017-0397-6.

Laidlaw, M. A. S., Gordon, C., \& Ball, A. S. (2018). Preliminary assessment of surface soil lead concentrations in Melbourne, Australia. Environmental Geochemistry and Health, 40(2), 637-650. https://doi.org/10.1007/s10653-017-0010-y.

Li, X. H., Wang, W., Wang, J., Cao, X. L., Wang, X. F., Liu, H. C., et al. (2008). Contamination of soils with organochlorine pesticides in urban parks in Beijing, China. Chemosphere, 70(9), 1660-1668. https://doi.org/10.1016/j. chemosphere.2007.07.078.

Liu, J., Xie, J. M., Chu, Y. F., Sun, C., Chen, C. X., \& Wang, Q. (2008). Combined effect of cypermethrin and copper on catalase activity in soil. Journal of Soils and Sediments, 8(5), 327-332. https://doi.org/10.1007/s11368-008-0029-x.

Lu, H. X., \& Liu, W. G. (2015). Characterization and risk assessment of polychlorinated biphenyls in City Park soils of Xi'An, China. Bulletin of Environmental Contamination and Toxicology, 94(3), 393-398. https://doi.org/10.1007 /s00128-015-1463-2.

Nasuti, C., Gabbianelli, R., Falcioni, M. L., Di Stefano, A., Sozio, P., \& Cantalamessa, F. (2007). Dopaminergic system modulation, behavioral changes, and oxidative stress after neonatal administration of pyrethroids. Toxicology, 229(3), 194-205. https://doi.org/10.1016/j.tox.2006.10.015.

Nasuti, C., Carloni, M., Fedeli, D., Gabbianelli, R., Di Stefano, A., Laura Serafina, C., et al. (2013). Effects of early life permethrin exposure on spatial working memory and on monoamine levels in different brain areas of pre-senescent rats. Toxicology, 303(0), 162-168. https://doi.org/10.1016/j. tox.2012.09.016.

Nelson, D. W. a. L. E. S. (1996). Total carbon, organic carbon, and organic matter. In A. L. Page (Ed.), Methods of Soil Analysis, Part 2, $2^{\text {nd }}$ ed. (Agronomy 9 ed.) (pp. 961-1010). Madison: Am. Soc. of Agron., Inc..

Nicolopoulou-Stamati, P., Maipas, S., Kotampasi, C., Stamatis, P., \& Hens, L. (2016). Chemical pesticides and human health: the urgent need for a new concept in agriculture. Frontiers in Public Health, 4, 148. https://doi.org/10.3389 /fpubh.2016.00148.

Palmquist, K., Salatas, J., \& Fairbrother, A. (2012). Pyrethroid insecticides: use, environmental fate, and ecotoxicology. In D. F. Perveen (Ed.), Insecticides - Advances in integrated Pest management. INTECH Open Access Publisher. http://www.intechopen.com/books/insecticides-advances-inintegrated-pest-management/pyrethroidinsecticides-useenvironmental-fate-and-ecotoxicology. Accessed December 2008.

Pastor-Belda, M., Navarro-Jimenez, T., Garrido, I., Vinas, P., Campillo, N., Fenoll, J., et al. (2018). Magnetic solid-phase extraction or dispersive liquid-liquid microextraction for pyrethroid determination in environmental samples. Journal of Separation Science, 41(12), 2565-2575. https://doi. org/10.1002/jssc. 201800109.

Pfeil, R. (2014). Pesticide Residues: Pyrethroids, in Encyclopedia of Food Safety, Yasmine Motarjemi, (Ed.). ISBN: 9780123786135, Waltham: Academic Press: 31-34.

Ponavic, M., Wittlingerova, Z., Coupek, P., \& Buda, J. (2018). Soil geochemical mapping of the central part of Prague, Czech Republic. Journal of Geochemical Exploration, 187, 118-130. https://doi.org/10.1016/j.gexplo.2017.09.008.

Rambla-Alegre, M., Esteve-Romero, J., \& Carda-Broch, S. (2012). Is it really necessary to validate an analytical method or not? That is the question. Journal of Chromatography A, $1232,101-109$. https://doi.org/10.1016/j. chroma.2011.10.050.

Soderlund, D. M. (2010). Toxicology and mode of action of pyrethroid insecticides. In R. Krieger (Ed.), Hayes' handbook of pesticide toxicology (third edition) (pp. 1665-1686). New York: Academic Press.

Vera, J., Correia-Sá, L., Paíga, P., Bragança, I., Fernandes Virgínia, C., Domingues Valentina, F., et al. (2013). QuEChERS and soil analysis. An overview. Sample Preparation, 1, 54.

Wahid, F. A., Wickliffe, J., Wilson, M., Van Sauers, A., Bond, N., Hawkins, W., et al. (2017). Presence of pesticide residues on produce cultivated in Suriname. Environmental Monitoring and Assessment, 189(6), 303. https://doi.org/10.1007 /s10661-017-6009-0.

Wang, W., Delgado-Moreno, L., Conkle, J. L., Anderson, M., Amrhein, C., Ye, Q. F., et al. (2012). Characterization of sediment contamination patterns by hydrophobic pesticides to preserve ecosystem functions of drainage lakes. Journal of Soils and Sediments, 12(9), 1407-1418. https://doi. org/10.1007/s11368-012-0560-7.

Weston, D. P., Holmes, R. W., You, J., \& Lydy, M. J. (2005). Aquatic toxicity due to residential use of pyrethroid insecticides. Environmental Science \& Technology, 39(24), 97789784. https://doi.org/10.1021/es0506354.

Weston, D. P., Ding, Y., Zhang, M., \& Lydy, M. J. (2013). Identifying the cause of sediment toxicity in agricultural sediments: the role of pyrethroids and nine seldommeasured hydrophobic pesticides. Chemosphere, 90(3), $958-964$. https://doi.org/10.1016/j. chemosphere.2012.06.039.

Woudneh, M. B., \& Oros, D. R. (2006). Pyrethroids, pyrethrins, and piperonyl butoxide in sediments by high-resolution gas chromatography/high-resolution mass spectrometry. Journal of Chromatography A, 1135(1), 71-77. https://doi. org/10.1016/j.chroma.2006.09.017.

Zhang, W., Jiang, F., \& Ou, J. (2011). Global pesticide consumption and pollution: with China as a focus. Proceedings of the International Academy of Ecology and Environmental Sciences, 1(2), 125-144. 